\title{
Avaliação de compostos com atividade antioxidante em células da levedura Saccharomyces cerevisiae
}

\author{
Daniele Grazziotin Soares, Ana Cristina Andreazza, Mirian Salvador ${ }^{1 *}$
}

${ }^{1}$ Instituto de Biotecnologia e Departamento de Ciências Biomédicas, Universidade de Caxias do Sul, Caxias do Sul, RS

"Correspondência:

M. Salvador

Instituto de Biotecnologia/Universidade

de Caxias do Sul

Rua Francisco Getúlio Vargas, 1130 -

Bairro Petrópolis

95001-970 - Caxias do Sul- RS

E-mail:msalvado@ucs.br
Antioxidantes são compostos que atuam inibindo elou diminuindo os efeitos desencadeados pelos radicais livres e compostos oxidantes. Diferentes métodos têm sido desenvolvidos para obter a diferenciação, seja qualitativa ou quantitativa, da capacidade antioxidante de compostos, tanto através de testes sem a utilização de células (testes químicos) ou utilizando culturas celulares (testes biológicos). Os testes químicos são mais rápidos e simples de serem executados. No entanto, não são representativos das condições celulares do homem. Ensaios microbianos 'in vivo' utilizando-se, principalmente, células eucarióticas da levedura Saccharomyces cerevisiae têm se mostrado muito adequados para determinação da capacidade antioxidante de diferentes compostos, fornecendo resultados rápidos, reprodutiveis e passiveis de serem correlacionados ao observado no homem. O objetivo deste trabalho foi avaliar a capacidade antioxidante do ácido L-ascórbico, vitamina $E$ ( $\alpha$-tocoferol) e dos flavonóides hesperidina, naringina, naringenina, quercetina, rutina e sakuranetina, utilizando como modelo de sistema biológico a levedura S. cerevisiae. Para realização dos testes, as células foram tratadas com o agente estressor apomorfina em presença e ausência das amostras. Os resultados mostraram que a rutina, hesperidina, sakuranetina, quercetina e naringina foram os compostos com maior atividade antioxidante, seguidos da naringenina e vitamina $E$. $O$ ácido $L$ ascórbico e a mistura de ácido L-ascórbico e vitamina $E$ não mostraram atividade antioxidante frente aos danos gerados pela apomorfina nas concentrações ensaiadas.
Unitermos

- Saccharomyces cerevisiae

- Antioxidantes

- Flavonóides

- Vitaminas

- Apomorfina

\section{INTRODUÇÃO}

Radicais livres (RL) e espécies reativas de oxigênio (ERO) desempenham papel fundamental no metabolismo celular. No entanto, quando em excesso, podem gerar estresse oxidativo, levando a alterações teciduais responsáveis por diversas patologias, incluindo o câncer (para revisão ver Dröge, 2002). Antioxidantes são substâncias que reagem com radicais livres impedindo ou diminuindo o estresse oxidativo e a conseqüente destruição tissular 
(Halliwell, Gutteridge, 2000). Entre os antioxidantes mais conhecidos estão as vitaminas, principalmente $\mathrm{C}$ e E e os flavonóides, entre os quais pode-se citar a quercetina, rutina, hesperidina, naringina, naringenina, e sakuranetina.

Por outro lado, entre os vários agentes oxidantes existentes está a apomorfina, um alcalóide semi-sintético de estrutura catecólica, capaz de formar radicais semiquinonas e quinonas (El-Bachá et al., 2000; Deleu et al., 2002; Garrido et al., 2002), responsáveis pela citotoxicidade do alcalóide em vários tipos de células (Lai, Yu, 1997; Mena et al., 1997; Blum et al., 2000).

Embora existam ensaios químicos (Peris et al., 1997; Espín et al., 2000; Fukumoto, Mazza, 2000) relativamente simples para avaliação da capacidade antioxidante, estes não são representativos das condições celulares do homem. Tendo em vista que antioxidantes assumem papel importante na medicina preventiva é necessário que as informações sejam obtidas a partir de sistemas biológicos.

A avaliação da capacidade antioxidante empregando animais de laboratório é, em geral, de difícil execução e necessita de um número elevado de animais para assegurar resultados estatisticamente significativos. Já os ensaios realizados com microorganismos são fáceis, rápidos e podem utilizar um grande número de células com as mesmas características genéticas. Várias razões tornaram a levedura Saccharomyces cerevisiae um dos melhores modelos de sistema eucariótico unicelular para estudos de estresse oxidativo. Seu metabolismo é semelhante ao de eucariotos superiores, com mecanismos próprios de ativação metabólica (citocromo P450) e de detoxificação, que não estão presentes em bactérias. Os ensaios em células eucarióticas permitem a avaliação da atividade antioxidante de inúmeros compostos de forma rápida, econômica e reprodutível e os resultados obtidos podem ser mais facilmente extrapolados para o homem, do que os obtidos em ensaios químicos (Henriques et al., 2001; Soares et al., 2003).

À vista disso, o objetivo deste trabalho foi avaliar a capacidade antioxidante de diferentes compostos frente aos danos causados pelo alcalóide apomorfina, utilizando como sistema biológico células eucarióticas da levedura $S$. cerevisiae.

\section{MATERIAL E MÉTODOS}

\section{Amostras}

Foram analisadas amostras de ácido L-ascórbico, vitamina $\mathrm{E}$ ( $\alpha$-tocoferol), ácido L-ascórbico adicionado de vitamina $E(1: 1)$, hesperidina, naringina, naringenina, quercetina, rutina e sakuranetina (todos E. Merck). As soluções dos antioxidantes foram preparadas na concentração $1 \mathrm{mM}$ ime- diatamente antes do uso, sendo que a vitamina $\mathrm{E}$ foi solubilizada em etanol $98 \%$ e água destilada estéril (2:3) e os demais antioxidantes em água destilada, deionizada e estéril. A concentração utilizada nos ensaios foi de $0,025 \mathrm{mM}$.

\section{Linhagem}

A linhagem utilizada foi a $S$. cerevisiae $X V$ 185-14C (MATa ade2-1, arg4-17, his1-7, lys1-1, trp5-48, hom3-10) gentilmente cedida pelo Dr. Von Borstel, do Departamento de Genética, Universidade de Alberta, Canadá.

\section{Agente estressor}

Como agente estressor foi utilizado o alcalóide isoquinolínico apomorfina (APO) (E. Merck) preparado em água destilada, deionizada e estéril na concentração $2 \mathrm{mM}$. A concentração final empregada nos testes foi de $0,2 \mathrm{mM}$.

\section{Meios de cultura e soluções}

Para a cultura das células da levedura empregou-se meio líquido completo YEPD contendo $1 \%(\mathrm{p} / \mathrm{v})$ de extrato de levedura, $2 \%(\mathrm{p} / \mathrm{v})$ de peptona e $2 \%(\mathrm{p} / \mathrm{v})$ de glicose (todos Difco Lab.). Para ressuspensão e diluição das células foi empregada solução de $\mathrm{NaCl}$ (Reagen) $0,9 \%$ $(\mathrm{p} / \mathrm{v})$. A determinação do número de células viáveis foi feita através de plaqueamento em meio YEPD solidificado com $2 \%(\mathrm{p} / \mathrm{v})$ de bacto ágar (E. Merck).

\section{Determinação da atividade antioxidante dos compostos}

Para a determinação da atividade antioxidante, $2 \times 10^{7}$ células $/ \mathrm{mL}$ provenientes da fase estacionária de crescimento, foram tratadas com as soluções de antioxidantes em presença e ausência de apomorfina. Após incubação a $28^{\circ} \mathrm{C}$ por 21 horas, as células tratadas, o controle de células e o controle de solvente (etanol) foram plaqueados em meio YEPD. As placas foram incubadas a $28^{\circ} \mathrm{C}$ por 48 horas. Após este período, foram contadas as colônias em cada placa e determinados os percentuais de sobrevivência celular. Os testes foram repetidos três vezes para cada antioxidante testado.

\section{Análise estatística}

Os resultados foram submetidos a tratamento estatístico através da análise de variância e pós-teste de Tuckey, utilizando-se o programa SPSS 10.0 for Windows. 


\section{RESULTADOS}

A análise dos resultados foi realizada comparandose os valores percentuais de sobrevivência da levedura $S$. cerevisiae tratada somente com apomorfina e com este agente estressor adicionado dos diferentes compostos. A concentração dos antioxidantes utilizada neste trabalho $(0,025 \mathrm{mM})$ foi a maior concentração não citotóxica para a levedura S. cerevisiae. O controle do solvente utilizado na solubilização da vitamina $\mathrm{E}$ (etanol) não se mostrou citotóxico nas condições ensaiadas (dados não mostrados).

A Tabela 1 apresenta os valores de sobrevivência da levedura $S$. cerevisiae tratada com apomorfina em presença e ausência dos diferentes antioxidantes. Não foram observadas diferenças estatisticamente significativas entre o controle de apomorfina e os testes realizados com o ácido L-ascórbico e a mistura de ácido L-ascórbico e vitamina E. Os flavonóides rutina, hesperidina, sakuranetina, quercetina e naringina mostraram o maior efeito antioxidante (estatisticamente similar), seguidos da naringenina e vitamina $\mathrm{E}$.

O cálculo do aumento do percentual de sobrevivência da levedura após tratamento com os antioxidantes foi realizado subtraindo-se os valores obtidos nos ensaios com os antioxidantes e a apomorfina daqueles obtidos somente com o agente estressor. Os flavonóides rutina, hesperidina, sakuranetina, quercetina, naringina e naringinina mostraram um aumento no percentual de sobrevivência de $58,20 \%, 55,20 \%, 53,00 \%, 51,30 \%, 46,50 \%$
TABELA I - Valores de sobrevivência da levedura Saccharomyces cerevisiae tratada com apomorfina $0,2 \mathrm{mM}$ em ausência e presença de soluções $0,025 \mathrm{mM}$ dos diferentes antioxidantes

\begin{tabular}{lc}
\hline Tratamentos & Sobrevivência (\%) $\pm \mathbf{D P}$ \\
\hline Apomorfina & $24,30 \pm 4,80^{\mathrm{c}^{*}}$ \\
Ácido ascórbico e vitamina E & $30,10 \pm 2,78^{\mathrm{c}}$ \\
$\quad$ apomorfina & \\
Ácido ascórbico + apomorfina & $34,35 \pm 1,92^{\mathrm{c}}$ \\
Vitamina E + apomorfina & $50,80 \pm 0,85^{\mathrm{b}}$ \\
Naringenina + apomorfina & $56,30 \pm 6,25^{\mathrm{b}}$ \\
Naringina + apomorfina & $70,80 \pm 2,20^{\mathrm{a}}$ \\
Quercetina + apomorfina & $75,60 \pm 3,81^{\mathrm{a}}$ \\
Sakuranetina + apomorfina & $77,30 \pm 1,41^{\mathrm{a}}$ \\
Hesperidina + apomorfina & $79,50 \pm 1,86^{\mathrm{a}}$ \\
Rutina + apomorfina & $82,50 \pm 0,14^{\mathrm{a}}$ \\
\hline
\end{tabular}

* Letras diferentes correspondem a diferenças estatísticas significativas pelo teste de Tuckey, para $p \leq 0,05$. Os resultados referem-se a média de 3 repetições para cada teste.

e $32,00 \%$, respectivamente, indicando um importante efeito antioxidante frente aos danos gerados pela apomorfina. A vitamina E, ácido L-ascórbico e a mistura, em proporções iguais de ácido L-ascórbico e vitamina E, mostraram-se se menos eficazes do que os flavonóides testados (Figura 1).

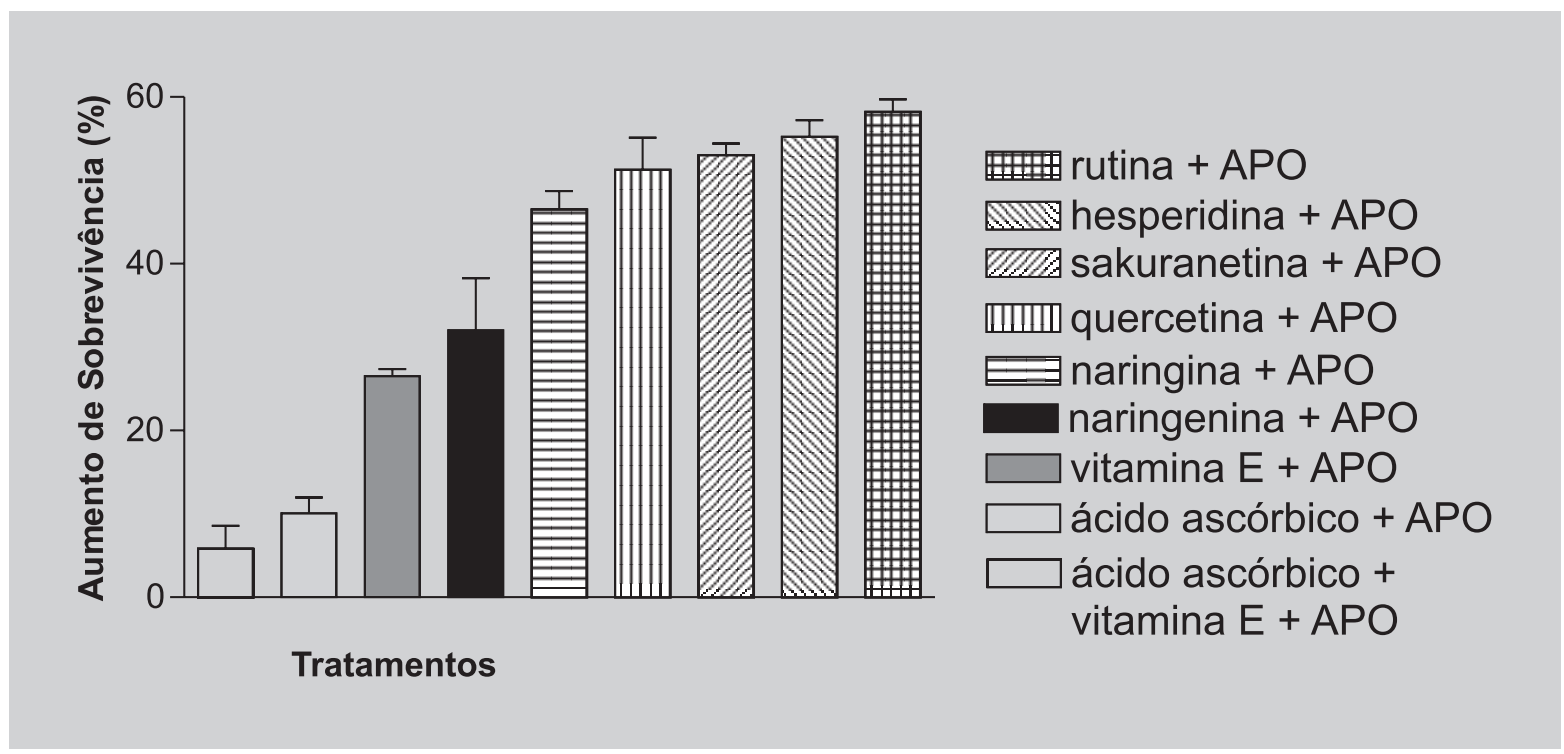

FIGURA 1 - Aumento do percentual de sobrevivência da levedura Saccharomyces cerevisiae nos tratamentos com os diferentes antioxidantes $(0,025 \mathrm{mM})$ e apomorfina $(0,2 \mathrm{mM})$. 


\section{DISCUSSÃO}

Neste trabalho mostrou-se que a capacidade antioxidante dos flavonóides foi superior à apresentada pelo ácido L-ascórbico e vitamina E em células eucarióticas da levedura $S$. cerevisiae tratadas com apomorfina. Resultados semelhantes foram obtidos em células de mamíferos, nas quais os flavonóides apresentaram capacidade antioxidante superior a do ácido Lascórbico e $\alpha$-tocoferol (Schimitt et al., 1995; Rice-Evans et al., 1996; Noorozi et al. 1998).

Embora o mecanismo de ação antioxidante dos flavonóides não esteja totalmente esclarecido e possa variar de acordo com a estrutura química do composto (Yuting et al., 1990; Guo et al., 1999), de modo geral, os flavonóides são capazes de doar hidrogênio para os radicais livres, estabilizando-os e impedindo o estresse oxidativo capaz de gerar danos tissulares ou morte celular (Chen et al., 1990; Saija, 1995; Jovanovic et al., 1998). Além disso, alguns flavonóides podem complexar-se com metais, tais como o $\mathrm{Fe}^{3+}$ e o $\mathrm{Cu}^{2+}$, evitando/diminuindo a geração de radicais hidroxila pela reação de Haber-Weiss/ Fenton (Halliwell, Gutteridge, 2000). Considerando que a geração de radicais semiquinonas e quinonas pela apomorfina é mediada por metais de transição (Kalyanaraman et al., 1985; Miller et al., 1990), é possível que a capacidade quelante dos flavonóides tenha contribuído para sua atividade antioxidante.

O ácido L-ascórbico, que não foi capaz de evitar os efeitos citotóxicos gerados pela apomorfina, embora descrito como um bom antioxidante in vitro, apresenta um papel controverso in vivo (Aragon, Tessier, 2003), o qual vem sendo atribuído a sua possível atividade pró-oxidante (Rietjens et al., 2002; Quiles et al., 2002). Estudos adicionais são necessários para esclarecer completamente os mecanismos oxidante/antioxidante deste composto.

Embora estudos em células de mamíferos tenham mostrado a existência de sinergismo entre as vitaminas $\mathrm{C}$ e E (Liu et al., 1998), os ensaios em levedura realizados neste trabalho não comprovaram este fato. Deve ser salientado, no entanto, que a determinação da capacidade antioxidante de um composto depende de vários fatores, como por exemplo, do tipo de teste utilizado, do agente estressor escolhido e das condições de solubilidade do meio, entre outros.

Os hábitos alimentares da população brasileira são bastante diversificados. No entanto, de modo geral, a ingestão diária de flavonóides (cerca de $23 \mathrm{mg} / \mathrm{dia}$ ) excede àquela de outros antioxidantes como a de $\beta$-caroteno (2$3 \mathrm{mg} /$ dia) e vitamina E (7-10 mg/dia) (Herrmann, 2002).
Assim sendo, os flavonóides representam uma contribuição importante ao potencial antioxidante da dieta. Estudos epidemiológicos mostraram relação entre o consumo de frutas e verduras e a proteção contra vários tipos de câncer (Zeiger, 1991; Block, 1992) doenças isquêmicas (Gramezzi et al, 1990) e diabetes (Colditz, 1992). Embora outros estudos sejam necessários, principalmente acerca do mecanismo de ação, absorção, metabolização, excreção e toxicidade, os dados obtidos neste trabalho reforçam a importância dos flavonóides como antioxidantes, tanto em dietas como em terapias de suplementação antioxidante.

\section{ABSTRACT}

\section{Evaluation of compounds with antioxidant activity in Saccharomyces cerevisiae yeast cells}

Antioxidants are compounds that remove free-radicals or minimize their availability to generate oxidative stress. There are many methods to determine antioxidant capacity, but microbiological assays, using mainly eukaryotic cells, have shown similar results to man. The purpose of this work was to evaluate, through biological tests, the antioxidant capacity of $L$ - ascorbic acid, vitamin $E$ ( $\alpha$-tocopherol) and the flavonoids hesperidin, naringin, naringenin, quercetin, rutin and sukuranetin. The study was carried out on eukaryotic cells of the yeast Saccharomyces cerevisiae treated with the above mentioned antioxidants in the presence of the stressing agent apomorphine. The results obtained showed that rutin, hesperidin, sakuranetin, quercetin and naringin were the most effective/potent antioxidant compounds followed by naringenin and $\alpha$-tocopherol. Vitamin $C$ and a mixture of vitamins $C$ and $E$ did not show antioxidant activity against apomorphine in the performed conditions of this work.

UNITERMS: Saccharomyces cerevisiae. Antioxidants. Flavonoids. Vitamins. Apomorphine.

\section{AGRADECIMENTOS}

\section{PPGP/UCS, CAPES e FAPERGS}

\section{REFERÊNCIAS BIBLIOGRÁFICAS}

ARAGON, B. I.; TESSIER, F. J. Antioxidant vitamins and degenerative pathologies a review of vitamin C. J. Nutr., v. 1,p.103-109, 2003. 
BLOCK, G.; PATTERSON, B.; SUBAR, A. Fruit, vegetables and cancer prevention: a review of the epidemiological evidence. Nutr. Cancer, v. 17, p. 1-29, 1992.

BLUM, D.; TORCH, S.; NISSOU, M.F.; BANABIB, A.L.; VERNA, J.M. Extracellular toxicity of 6hydroxydopamine on PC12 cells. Neurosci. Lett., v. 283, p. 193-196, 2000.

CHEN, Y.; ZHENG, R.; JIA, Z.; JU, Y. Flavonoids as superoxide scavengers and antioxidants. Free Rad. Biol. Med., v. 9, p.19-21, 1990.

COLDITZ, G.A.; MANSON, J. E.; STAMFER, M. J.; ROSNER, B.; WILLETT, W.; SPIEZER, F. E. Diet and risk of clinical diabetes in women. Am. J. Clin. Nutr., v. 55, p. 118-23, 1992.

DELEU, D.; NORTHWAY M.G.; HANSSENS Y. Clinical pharmacokinetic and pharmacodynamic properties of drugs used in the treatment of Parkinson's disease, Clin. Pharmacokinet, v. 41, p. 261-309, 2002.

DRÖGE, W. Free radicals in the physiological control of cell function. Phys. Rev., v. 82, p. 47-95, 2002.

EL-BACHÁ, R.S.; LECLERC S.; NETTER P.; MAGDALOU J.; MINN, A. Glucuronidation of apomorphine, Life Sci., v. 67, p. 1763-1745, 2000.

ESPÍN, J.C.; SOLER-RIVAS, C.; WICHERS, H.J. Characterization of the total free scavenger capacity of vegetable oils and oil fractions using 2,2 diphenyl-1picrylhydrazyl radical. J. Agric. Food Chem., v. 48, p. 648-656, 2000.

FUKUMOTO, L.R.; MAZZA, G. Assessing antioxidant and prooxidant activities of phenolic compounds. J. Agric. Food Chem., v. 48, n. 8, p. 3597-3604, 2000.

GARRIDO J.M.P.J.; DELERUE-MATOS C.; BORGES M.F.M.; MACEDO, T.R.A.; OLIVEIRA-BRETT, A.M. Oxidative behaviour of apomorphine and its metabolites, Bioelectrochem., v. 55, p. 113-114, 2002.

GRAMEZZI, A.; GENTOLA, A.; FASOLI, M. Assossiation between certain food and risk of acute myocardial infartion in women. Br. Med. J., v. 300, p. 771-773, 1990.
GUO, Q.; ZHAO, B.; PACKER, L. Electron spin resonance study of free radicals formed from a procyanidin-rich pine (Pinus maritima) bark extract, pycnogenol. Free Rad. Biol. Med., v. 27, p. 1308 - 1312, 1999.

HALLIWELL, B.; GUTTERIDGE, J.M.C. Free radicals in biology and medicine. 3 ed. Clarendon, Oxford, 2000. $936 \mathrm{p}$.

HENRIQUES, J.A.P.; DAFRÉ, A.L.; PICADA, J.N.; MARIS, A.F.; SALVADOR, M. Espécies reativas de oxigênio e avaliação de antioxidantes em sistemas biológicos. In: SERAFINI, L.A.; Barros, N.M.; AZEVEDO, J.L. (Eds.) Biotecnologia na Agricultura e na Agroindústria. Guaíba: Agropecuária, 2001. v.1, p. 227-252.

HERRMANN, M.S. Aspectos nutricionais dos flavonóides. In: Estresse oxidativo e antioxidantes. Porto Alegre: Ed. Ulbra, 2002. p.105-119.

JOVANOVIC, S.V., STREENKEN, S., SIMIC, M.G., HARA, Y.Antioxidant proprieties of flavonoids reduction potentials and electron transfer reactions of flavonoid radicals. In: Flavonoids in health and disease. New York: Marcel Dekker, 1998. p. 137-161.

KALYANARAMAN B.; FELIX C.C.; SEALY R.C. Semiquinone anion radicals of catechol(amine)s, catechol estrogens and their metal ion complexes. Environm. Health Perspec., v. 64, p. 185-198, 1985.

LAI, C.T.; YU, P.H. Dopamine and L- $\beta-3-4-$ dihydroxyphenylalanine hydrochloride (L-DOPA)induced cytotoxicity towards catecholaminergic neuroblastoma SH-SY5Y cells. Biochem. Pharmacol., v. 53, p. 317-328, 1997.

LIU, Z.Q.; MA, L. P.; LIU, Z. Making vitamin C lipophilic enhances its protective effect against free radical induced peroxidation of low density lipoprotein. Chem. Phys. Lip., v. 95, p. 49-57, 1998.

MENA, M.A.; CASAJEROS, M.J.; CARAZO, A.; PAÍNO, C.L., GARCIADE YÉBENES, J. Glia protect midbrain dopamine neurons in culture from L-DOPA toxicity through multiple mechanisms. J. Neural. Transm., v. 104, p. 317-328, 1997. 
MILLER D.M.; GARRY R.B.; AUST S. Transition metals as catalysts of "autoxidation"reactions. Free Rad. Biol. Med., v. 8, p. 95-108, 1990.

NOOROZI, M.; ANGERSON, W.;LEAN, M. E. L. Effects of flavonoids and vitamin $C$ on oxidative DNA damage to human lymphocytes, Am. J. Clin. Nutr., v. 67, p.1210$1218,1998$.

PERIS, F.; SACO,Y.; GAFO, C.; BASSOLS, A. Comparisons of two commercial kits for the enzymatic determination of nonesterified fatty acids in goat serum. Small Rum. Res., v. 26, p. 181-187, 1997.

QUILES, J. L.; HUERTAS, J. R.; BATTINO, M.; MATAIX, J.; RAMÍREZ-TORTOSA, M. C. Antioxidant nutrients and adriamycin toxicity. Toxicology, v. 180, p. 79-95, 2002.

RICE-EVANS, C. A.; MILLER, N. J.; PAGANGA, G. Structure-antioxidant activity relationships of flavonoids and phenolic acids. Free Rad. Biol. Med., v. 20, p. $933-$ 956, 1996.

RIETJENS, I. M. C. M.; BOERSMA, M. G.; HAAN, L.; SPENKELINK, B.; AWAD, H. M.; CNUBBEN, N. H. P.; ZANDEN, J. J.; WOUD, H.; ALINK, G. M.; KOEMAN, J. H. The pro-oxidant chemistry of the natural antioxidants vitamin $\mathrm{C}$, vitamin $\mathrm{E}$, carotenoids and flavonoids. Env. Toxicol. Pharmacol., v. 11, p. 321-333, 2002.
SAIJA, A.; SCALESE, M.; LANZA, M.; MARZULLO, D.; BONINA, F.; CASTELLI, F. Flavonoids as antioxidant agents: importance of their interaction with biomembranes. Free Rad. Biol. Med., v. 19, n. 4, p. 481486, 1995.

SCHIMITT, A.; SALAVAYRE, R.; DELCHAMBRE, J. Prevention by alfa- tocoferol and rutin of glutatione and ATP depletion induced by oxidized LDL inculture endothelial cells. Britsh J. Pharm., p. 1985-1990, 1995.

SOARES, D.G.; ANDREAZZA, A.C.; SALVADOR, M. Sequestering ability of butylated hydroxytoluene, propyl gallate, resveratrol, and vitamins $\mathrm{C}$ and $\mathrm{E}$ against $\mathrm{ABTS}$, $\mathrm{DPPH}$, and hydroxyl free radicals in chemical and biological systems. J. Agric. Food Chem., v. 51, n. 4, p.1077-1080, 2003.

YUTING, C.; RONGLIANG, Z.; ZHONGJIAN, J.; YONG, J. Flavonoids as superoxide scavengers and antioxidants. Free Rad. Biol. Med., v. 9, p. 19-21, 1990.

ZEIGER, R. Vegetables, fruits and carotenes and risk of cancer. Am. J. Clin. Nutr., v. 53, suppl. p. 251S-259S, 1991.

Recebido para publicação em 22 de novembro de 2002. Aceito para publicação em 04 de março de 2005. 